The present study has shown that a treatment given according to clinical experience may produce identical judgements of the results by the patient and by the physician. A pre-requisite for identical opinions is adequate information about the therapy and its possible consequences. ${ }^{3-5}$ This information should, preferentially, be given by the doctor directly to the patient. When informing patients suffering from painful conditions or degenerative conditions of the locomotor apparatus the risk of recurring symptoms/ signs should be considered.

Patients in coma or presenting disorientation at income were excluded from the study. Those recovering from these conditions after adequate therapy may judge the result of the treatment from a completely different point of view than the physician.

\section{References}

1 Speedling EJ, Rose DN. Building an effective doctorpatient relationship: From patient satisfaction to patient participation. Soc Sci Med 1985;21:115-20.

2 Carmel S. Satisfaction with hospitalization: A comparative analysis of three types of services. Soc Sci Med 1985;21:1243-49.

3 McGhee A. The Patient's Attitude to Nursing Care. 1961; London: Livingstone.

4 Cartwright A. Human Relations and Hospital Care. 1964; London: Routledge and Kegan Paul.

5 Houston C, Pasanen W. Patients perception of hospital care. Hospitals 1974;46:70-74.

\title{
Sir Victor Horsley's surgery for epilepsy
}

The first operation for a brain tumour' was probably performed by William Macewen on 27 July 1879 . The patient was a 14 year old girl with a left frontal convexity meningioma. By 1888, Macewen had reported another 11 brain operations, mostly for cysts, abscesses, tuberculomata, depressed fractures and haematoma. The most celebrated, but not the first operation, was the removal of a frontal glioma from the right ascending parietal convolution, on 25 November 1884 by Rickman Godlee, the nephew of Lord Lister.

Sir Victor Horsley (1857-1916) was a remarkable, versatile and individualistic genius. He is renowned for many feats of original surgery and for localisation of cortical physiology in collaboration, inter alia, with such giants as David Ferrier, Jackson, Beevor, Gowers, Clarke and Kinnier Wilson. His first surgery on the brain can be seen as the forerunner of modern surgery for epilepsy. His first patient James B, aged 22 years had sustained an infected depressed fracture at the age of 7 and later developed prolonged attacks of Jacksonian status epilepticus. On 25 May 1886 Horsley exposed the obvious lesion and removed a highly vascular scar 3 by $2 \mathrm{~cm}$. The fits did not recur. Hughlings Jackson and David Ferrier were in the theatre, as they had been for Godlee's operation. Jackson then suggested surgery for another of his patients, a Thomas W. in whom he had diagnosed epilepsy due to a cortical tuberculoma. Jackson proved correct, the lesion was excised and the patient survived another eight years. Horsley's third case was a stable boy who had endured a number of injuries to the head and consequent epilepsy. He had a tender old depressed fracture of the left parietal convexity and Horsley associated this with his unusual "rectal aura". Extensive debridement of the cortex and inner table of the skull was a success.

Horsley's incredible energies and achievements are delightfully described by Irving Cooper ${ }^{2}$ and by Stephen Paget ${ }^{3}$ and JB Lyons. ${ }^{4}$ He was named Victor Alexander after Queen Victoria at her own suggestion and passed on by a lady in waiting who was friend to Horsley's mother. He died tragically, aged 59, of fever, probably heat stroke in Amara on the Tigris campaign, for which he had courageously but unwisely volunteered at the age of 57, in 1914 .

\section{References}

1 Pearce JMS. The first attempts at removal of brain tumours. In: FC Rose and WF Bynum, eds. Historical Aspects of the Neurosciences, A Fetschrift for Macdonald Critchley. New York: Raven Press, 1982:239-43.

2 Cooper IS. Sir Victor Horsley: Father of Modern Neurological Surgery. ibid 235-39.

3 Paget S. Sir Victor Horsley. London: Constable \& Co, 1919.

4 Lyons JB. The Citizen Surgeon: A biography of Sir Victor Horsley. London: Dawnay, 1966. 